\title{
Humbling of world's AIDS researchers
}

\section{Last week's international conference on AIDS seems merely to have confirmed the impression of earlier conferences in the series - that science, for the time being, has little to say to those with AIDS.}

LAST week's conference in Amsterdam seems to have had more in common with the meeting there in May (see Nature 357, 188; 1992) than the organizers planned, or bargained for. In particular, as newspaper accounts of what happened have diligently recorded, some sessions were marked by open confrontation between people diagnosed as suffering from AIDS and researchers doing everything they can to understand this distressing condition and, eventually, to find ways of treating it. Drug companies such as the Wellcome Foundation (BurroughsWellcome in the United States) seem to have been especially ill-treated for making money out of AZT, the drug most often used for restraining the progress of the disease.

None of that is surprising. People in whom immune deficiency has already appeared, even if recognized only by a T-cell count, may feel that they necessarily exist on the margins of ordinary living space, never sure when they will be struck down by some adventitious infection. It is understandable that they should be enraged by what may seem a cruel fate, made no easier to bear by the inclination of others to regard them as outcasts. That many of those in this condition may also be united with groups of like-minded people by practices that may have contributed to their contracting the disease in the first place makes it inevitable that individual rage will be collectivized. It is not reasonable to expect them to behave as saintly Christian martyrs.

That much of the rage may be directed against researchers is also unsurprising. When AIDS was first distinguished as a disease entity more than a decade ago, consternation was appropriate. By 1984, when the association of AIDS with HIV (as the virus is now called) had been recognized, it was forgivable (if injudicious) of Mrs Margaret Heckler, then the US Secretary of Health and Human Services, to speculate about the production of a vaccine.

That promise, for one, has not yet materialized. Whether it ever will remains to be seen. It is good news, from last week, that several vaccines have already been tested on volunteers not infected with HIV, without untoward consequences. It will be some time longer before anybody can tell whether such agents are likely to be useful in the treatment of those already suffering from AIDS, or whether they can be used only prophylactically, and presumably only in the rich countries of the world.

Other promises widely understood to be implicit in the biomedical research enter- prise have similarly failed to materialize. Why is there no drug (except AZT, and its few analogues now making their way into clinical practice)? Why is there no magic bullet, perhaps a ribozyme, specific in its action against HIV, which leaves other nucleotide sequences intact? And if there is, as some say, an intimate connection between the efficacy of the immune system and the working of the pituitary gland, as proxy for the mind's ambitions, why have people not yet devised the way of thinking one's way out of trouble caused by AIDS?

Sadly, there is no one-to-one relationship between disease entities and drugs that will cure them. The hunt for magic ribozymes has been tried unsuccessfully, and will no doubt be tried again (but drug delivery will not be easy). And psychoimmunology, despite the benefits there would be if it could be demonstrated to be other than an autonomous connection, has been ineffectual in dealing with far simpler diseases than AIDS.

The decade's gap between the recognition of AIDS and the present is not in itself remarkable, of course. Tuberculosis may have been recognized to be an infection soon after Pasteur, when measures such as the relative isolation of patients and the exercise of their lungs helped reduce the death toll, but effective measures against the disease in situ have been available only for the past half-century.

Most infections more recently recognized as such have been more quickly dealt with. The successful containment of poliomyelitis, even in the poor countries, is only the most dramatic of a string of successes. By 1984, it had become everybody's instinct to suppose that most infections were curable one way or another. One of the reasons why the research community is now pilloried by those with AIDS is that much the same was promised, or was assumed, for the treatment and even cure of AIDS.

But why blame the research community for that? The question, however plaintive, is reasonable enough. The trouble is that it cannot confidently be answered in the sense researchers would wish. While everybody accepts that there are intellectual problems about the world we live in that are for the time being insoluble, there is a tendency to suppose that mere practical problems fixing a machine or curing a disease - can be simply dealt with. One lesson usefully to be learned from the the past decade's disappointment over AIDS is that researchers should be more diligent in the repetition of what everybody knows - that uncertainty is always with us. The collective anger of the activists at Amsterdam may be a lasting reminder of that.

Last week's conference seems to have been humbling in another way; this year, there was no great leap forward in understanding to report. No doubt that is why so much attention was paid, at least by European daily newspapers, to reports of people apparently suffering from AIDS in whom no trace of HIV can be found. Does that mean that Duesberg has been right all along, and that HIV plays no part in the causation of AIDS?

Mercifully, most people appear to have appreciated that that conclusion would be false. For one thing, it is too soon to know what will be made of these observations when eventually they are published, some apparently in the next week or so. But there are several explanations, one of which is that severe (and, if untreated, fatal) immunodeficiency long predates the discovery of HIV, but is evidently distinct from the rash of cases that made their first appearance in San Francisco in the late 1970s. Awareness of AIDS (and the ease with which $T$-cell status can now be assessed) could easily have helped to bring cases of that kind to the attention of physicians. But it is also possible that cases of AIDS without traces of HIV reflect circumstances in which the virus has done its nasty work by triggering a secondary failure of the immune system and has then itself been eliminated from the cells at risk. And, of course, there is always the possibility of experimental error.

What will happen next? Many of the participants in last week's meeting found the occasion enervating, while the views of those who still believe that something dramatic will turn up sound more and more Micawber-like. On balance, the view that there is a long haul ahead predominates.

Participants are also divided on the question whether, at future conferences in this series, there should be an attempt to separate the presentation of research work from the educational function of enabling AIDS organizations to mix with those in whose hands their clients' lives may rest. While some researchers would prefer a setting in which they could understand what their peers are saying, more would prefer not to be thought to have ducked confrontation.

Next year's meeting has been arranged for Berlin, after which the conferences will probably happen every other year. How long will it be before there is a hopeful conference?

John Maddox 